\title{
Hepatic Lesions in Experimental Campylobacter jejuni Infection of Mice
}

\author{
By EIJI KITA, ${ }^{1}$ * NORIAKI KATSUI, ${ }^{1}$ KAZUYUKI NISHI, ${ }^{1}$ \\ MASASHI EMOTO, ${ }^{2}$ YASUO YANAGASE ${ }^{3}$ AND SHUZO KASHIBA ${ }^{1}$ \\ ${ }^{1}$ Department of Bacteriology, Nara Medical College, Kashihara, Nara, Japan \\ ${ }^{2}$ Ösaka Kessei, Nara Clinical Research Laboratory, Kashihara, Nara, Japan \\ ${ }^{3}$ Department of Bacteriology, Hyogo College of Medicine, Nishinomiya, Hyogo, Japan
}

(Received 30 December 1985; revised 12 June 1986)

\begin{abstract}
Mice orally infected with Campylobacter jejuni developed focal infiltrative necrotic lesions in the liver, as determined by both histology and liver function tests. The initial histopathological feature was a focal infiltrative lesion in the parenchyma and portal triads. Foci of infiltrative lesions became necrotic between days 30 and 60 post-inoculation (p.i.). During this period, portal infiltrates increased in severity. From month 4 p.i., focal areas of infiltrative necrosis in the liver parenchyma became extensive. Study of liver function demonstrated mild elevations of transaminases, alkaline phosphatase and lactic dehydrogenase, and also the presence of hypoalbuminaemia. Although histopathological changes of the liver became gradually more marked after day 30 p.i., liver functions of infected mice were most affected at 2 months p.i. The capacity of $C$. jejuni to induce hepatic lesions seemed to be related to that of organisms to persist in the gall bladder; there was no correlation between biliary carriage in infected mice and positive faecal culture.
\end{abstract}

\section{INTRODUCTION}

Campylobacter jejuni has been reported as being capable of producing a heat-labile enterotoxin (Ruiz-Palacios et al., 1983) having close immunological relatedness with Escherichia coli heat-labile toxin (LT) and cholera toxin (Blaser et al., 1979; Klipstein \& Engert, 1984). Although enterotoxigenicity of $C$. jejuni is recognized as one of its virulence attributes, the organism can clearly be invasive (Lambert et al., 1979; Drake et al., 1981; Ruiz-Palacios et al., 1981; Caldwell et al., 1983). In man, only $20-30 \%$ of patients with campylobacter enteritis have a clinical picture of intestinal invasion (Skirrow, 1977; Blaser et al., 1979; Butzler \& Skirrow, 1979; Drake et al., 1981), and in the majority illness is associated with secretory diarrhoea. The quantity of $C$. jejuni enterotoxin produced by clinical isolates varies widely, from none to large amounts (Ruiz-Palacios et al., 1983; Klipstein \& Engert, 1984). These findings suggest that the pathophysiology of $C$. jejuni enteric infection might not be uniform. Up to now, a definite mechanism of campylobacter enteritis has not been determined.

We found that some strains of $C$. jejuni could invade uterine epithelium and persist in the liver for several months after mice were inoculated intravaginally with $C$. jejuni (unpublished data). Also, it has been demonstrated that oral inoculation with $C$. jejuni can produce disseminated campylobacter infection in mice (Blaser et al., 1983). In the latter study, $C$. jejuni was isolated early post-inoculation (p.i.) from the liver, which had a major role in clearing $C$. jejuni from the bloodstream. We studied infected mice throughout 10 months following oral infection with $C$. jejuni and found that about $20 \%$ of them became emaciated between months 6 and 8 p.i., and that their livers showed macroscopic atrophy. The present study was therefore undertaken to clarify the pathological changes of the livers of mice orally infected with $C$. jejuni.

\footnotetext{
Abbreviations: ALP, alkaline phosphatase; GOT, glutamic-oxaloacetic transaminase; GPT, glutamic-pyruvic transaminase; LDH, lactic dehydrogenase; p.i., post-inoculation.
} 


\section{METHODS}

Bacterial strains. Campylobacter jejuni strain GIFU 8734 (serotype PEN 18) was kindly provided by Dr E. Yabuuchi (Department of Microbiology, Faculty of Medicine, Gifu University, Japan) and serotyped by Dr H. Nakanishi (Public Health Research Institute, Kobe City, Japan) with a passive haemagglutination assay (Penner \& Hennessy, 1980). Three other strains (DK, S-1, and 13) were clinical isolates from adult patients with campylobacter enteritis and exhibited typical biochemical characteristics of $C$. jejuni, including the ability to hydrolyse hippurate. The serotypes of these strains were PEN 1 (strain DK), PEN 2 (strain S-1) and PEN 4 (strain 13).

To prepare challenge inocula, strains were plated on $10 \%(\mathrm{v} / \mathrm{v})$ horse blood agar and incubated at $42{ }^{\circ} \mathrm{C}$ for $24 \mathrm{~h}$ in an anaerobic jar with a Gas-Pak (without catalyst) (BBL Microbiology Systems). Bacteria grown on plates were transferred into liquid medium composed of tryptose ( $2 \%, \mathrm{w} / \mathrm{v}, \mathrm{Difco}), \mathrm{K}_{2} \mathrm{HPO}_{4}(0.2 \%, \mathrm{w} / \mathrm{v}), \mathrm{NaCl}(0.6 \%, \mathrm{w} / \mathrm{v})$, soluble starch $(1 \%, \mathrm{w} / \mathrm{v})$ and L-cysteine $(0.02 \%, \mathrm{w} / \mathrm{v})$. After autoclaving, yeast extract (Difco) sterilized by filtration and $\mathrm{CO}_{2}$-saturated sodium biocarbonate were added to final concentrations of $1 \%(\mathrm{w} / \mathrm{v})$ and $0 \cdot 1 \%(\mathrm{w} / \mathrm{v})$, respectively. A 1-1 Erlenmeyer flask containing $400 \mathrm{ml}$ liquid medium plus inoculum was placed in a glass jar in which a microaerobic atmosphere was generated with a Gas-Pak, and incubated at $42{ }^{\circ} \mathrm{C}$ for $48 \mathrm{~h}$. Cells were harvested by centrifugation and washed once with phosphate-buffered saline $(0.136 \mathrm{M}-\mathrm{NaCl}, 2.6 \mathrm{mM}-\mathrm{KCl}$, $1.4 \mathrm{mM}-\mathrm{KH}_{2} \mathrm{PO}_{4}, 4.2 \mathrm{mM}-\mathrm{Na}_{2} \mathrm{HPO}_{4}, \mathrm{pH} 7.2$ ). Bacterial suspensions were standardized in PBS using a spectrophotometer. Serial dilutions to obtain colony counts were made by the method of Miles \& Misra (1938).

Animals. Female specific pathogen-free ddY mice, 5 to 7 weeks old, were purchased from Shizuoka Agricultural Cooperative Association for Laboratory Animals (Hamamatsu, Japan) and maintained on sterile pelleted food and water ad lib.

Infection of mice. Mice were infected orally by introducing $0.1 \mathrm{ml}$ of an appropriate dilution of culture directly and atraumatically into the stomach through a thin vinyl tube (Intramedic, Clay Adams) connected to a blunted 23-gauge needle. Care was taken that the inoculum was not accidentally discharged into the mouth or oesophagus. At daily intervals for $7 \mathrm{~d}$, fresh faecal specimens were directly cultured for $C$. jejuni on Skirrow's medium (Skirrow, 1977) at $42{ }^{\circ} \mathrm{C}$ in an anaerobic jar with a Gas-Pak (without catalyst) to determine the minimal infective dose of each strain for ddY mice.

To study hepatic lesions following infection, 80 mice were orally infected with $10^{7}$ c.f.u. of strain GIFU and kept 10 per cage. On days $1,3,5$, and 7 p.i., one mouse was randomly selected from each cage and all eight mice were examined for hepatic lesions. Groups of eight mice were then examined at $30 \mathrm{~d}$ intervals for 6 months.

Study of hepatic lesions and processing of livers to obain bacterial counts. To avoid haemorrhage and dilation of sinusoids in the liver, the eight mice were killed by puncturing the retro-orbital venous plexus at each sampling time. Serum samples were separated from clotted blood at $4{ }^{\circ} \mathrm{C}$ and stored at $-70{ }^{\circ} \mathrm{C}$ prior to use. The intestinal mucosae were scraped, and intestinal contents were obtained. Faecal specimens and intestinal contents were suspended, diluted with tryptic soy broth containing $0.02 \%(w / v)$ L-cysteine, plated onto Skirrow's medium and then incubated at $42{ }^{\circ} \mathrm{C}$ for $48 \mathrm{~h}$ in a microaerobic atmosphere $\left(5 \%, \mathrm{v} / \mathrm{v}, \mathrm{O}_{2}\right)$.

The liver was aseptically removed from four mice, kept in $1 \mathrm{ml}$ warmed tryptic soy broth supplemented with $0.02 \% \mathrm{~L}$-cysteine in a Petri dish and then carefully minced with scissors to make the specimens homogeneous. The Petri dishes were kept at $37^{\circ} \mathrm{C}$ for $15 \mathrm{~min}$ and serial dilutions of homogenates were cultured on Skirrow's medium in a microaerobic atmosphere $\left(5 \% \mathrm{O}_{2}\right)$ at $42{ }^{\circ} \mathrm{C}$ for $48 \mathrm{~h}$.

The remaining four mice were used for histology. One lobe of the liver was removed to culture $C$. jejuni; the other lobes were fixed in $10 \%(\mathrm{w} / \mathrm{v})$ formaldehyde solution or in ethanol/acetic acid $(95: 1, \mathrm{w} / \mathrm{v})$ at $4^{\circ} \mathrm{C}$ for immunofluorescence tests. Tissues were embedded in paraffin, sectioned (2-3 $\mu \mathrm{m}$ thickness), and stained with haematoxylin and eosin. All slides were read by two of us without knowing the origin of the sample. Multiple sections were examined blindly for each mouse.

Gall bladders were separately removed, minced in a sterile polystyrene tube $11 \mathrm{~mm}$ diameter, Sumitomo Bakelite Co., Tokyo) containing $0.5 \mathrm{ml}$ tryptic soy broth supplemented with L-cysteine and cultured as described.

Direct immunofiuorescence. Slides of liver sections were incubated with fluorescein-labelled rabbit anti- $C$. jejuni strain GIFU immunoglobulin prepared by the method of Johnson et al. (1978). The labelled immunoglobulin was preabsorbed with normal mouse liver homogenates. Preparations were observed with an Olympus epifluorescence ultraviolet microscope. Control slides containing Escherichia coli and liver tissues from uninfected animals showed no specific immunofluorescence.

Liver function tests. Liver function of infected mice was monitored by measuring the following enzyme activities: serum glutamic-oxaloacetic transaminase (EC 2.6.1.1; GOT), serum glutamic-pyruvic transaminase (EC 2.6.1.2; GPT), alkaline phosphatase (EC 3.1.3.1; ALP) and lactic dehydrogenase (EC 1.1.1.27; LDH). Transaminases were measured by the method of Karmen et al. (1955), ALP by the method of Kind \& King (1954) and LDH by the method of Amador et al. (1963). All function tests were analysed on a Hitachi 706D autoanalyser. Serum albumin was measured by an electrophoretic method (Kohn, 1958).

Control experiments. Normal mice (80) of the same age as the infected mice were kept 10 per cage in the same 
animal house as that used for the infected mice. At each of the described intervals, one of them was randomly selected from each cage and all eight mice were used as controls. Data from uninfected mice of challenged groups were also recorded.

\section{RESULTS}

\section{Virulence of four Campylobacter strains in mice}

Comparison of the minimal infective dose for four strains of $C$. jejuni, as determined by faecal culture positivity during the $7 \mathrm{~d}$ p.i., is shown in Table 1 . All mice became infected with oral doses greater than $10^{8}$ c.f.u. of strains GIFU and S-1. A dose of $10^{5}$ c.f.u. of these strains resulted in colonization in $60 \%$ of mice by day 7 . Mice infected with $10^{9}$ c.f.u. of strain 13 excreted $C$. jejuni in their stools for only $2 \mathrm{~d}$ after inoculation; similar results were obtained with strain DK (Table 1). In subsequent studies with 80 mice, an oral dose of $10^{7}$ c.f.u. of strain GIFU was used because this dose consistently induced faecal culture positivity in $100 \%$ of mice. The four campylobacter strains did not cause marked diarrhoea in mice.

\section{Enumeration of $C$. jejuni in organs}

Qualitative cultures of organ specimens for $C$. jejuni after oral inoculation of strains GIFU $\left(10^{7}\right.$ c.f.u. $)$ and DK $\left(10^{8}\right.$ c.f.u. $)$ are shown in Table 2 . In the alimentary tract, the small intestine was the major site of colonization by $C$. jejuni. Faecal culture positivity for strain GIFU decreased to less than $50 \%$ between days 30 and 60 p.i. By day 30 p.i., strain DK colonized only the small intestine, and had disappeared from the faeces. However, both strains could be recovered from the hepatobiliary tract at this time. Both strains were recovered from the gall bladder between days 30 and 180 p.i., and even at 6 months p.i. six mice $(75 \%)$ were biliary carriers. No organisms could be recovered from blood samples during these experiments and blood cultures for $C$. jejuni were all negative, even at earlier times (10 and $60 \mathrm{~min})$ after inoculation.

The results of quantitative cultures of organ specimens for $C$. jejuni after inoculation with strain GIFU are shown in Table 3. On day 5 p.i., $C$. jejuni was recovered from the liver and gall bladder but the number of c.f.u. per $\mathrm{g}$ tissue in these organs was maximal between days 30 and 60. C. jejuni had disappeared from the colon contents 2 months after inoculation and the caecum was colonized with about 100 c.f.u. of $C$. jejuni per $\mathrm{g}$ tissue at this time. The upper half of the intestinal tract was colonized more densely than the lower half.

\section{Histological changes in the liver}

Light microscopy. At 2 weeks p.i., a minimal histological change, characterized by an inflammatory cell infiltrate around the central veins with an increase in prominence of Küpffer cells, was observed (Fig. 1 a). At 1 month p.i., there were some focal changes of the parenchyma. These consisted of an increased cytoplasmic staining intensity and pyknotic nuclei of hepatocytes (Fig. $1 b$ ), although the liver architecture was preserved. The initial changes became focal necrosis with inflammatory cell responses between days 30 and 60 p.i. (Fig. 1c). During this period, inflammatory nodules became marked in portal triads (Fig. $1 d$ ), and the number of focal lesions increased. At 3 months p.i., an inflammatory cell response around the central veins became intense (Fig. 1e). The inflammatory nodules in portal triads became extensive from 4 months p.i. (Fig. $1 f$ ). The gall bladder became enlarged at 4 months p.i. and the epithelial layer was oedematous (Fig. $1 \mathrm{~g}$ ). Between months 4 and 6 , focal areas of infiltrative necrosis became extensive (Fig. $1 h$ ). There were no significant differences in histology of the liver between mice infected with strains GIFU and DK. Furthermore, uninfected mice of challenged groups showed no pathological changes in the liver and gall bladder at any time.

Immunofluorescence. Campylobacter organisms were observed reaching the liver as early as $5 \mathrm{~d}$ p.i. By $7 \mathrm{~d}$, specific fluorescence was seen in the sinusoids and around the portal triads. The intensity of specific responses was most prominent between days 30 and 60 p.i. (Fig. 2). The intensity of specific fluorescence decreased thereafter in accordance with a decrease in the culture positivity of liver specimens. Specific fluorescence was not seen in any hepatic 
Table 1. Comparison of the minimal infective dose for four strains of $C$. jejuni

\begin{tabular}{|c|c|c|c|c|c|c|c|c|}
\hline \multirow{3}{*}{$\begin{array}{l}\text { Dose } \\
\text { (c.f.u.) }\end{array}$} & \multicolumn{8}{|c|}{ Infection rate* } \\
\hline & \multicolumn{4}{|c|}{ Day 3 p.i. } & \multicolumn{4}{|c|}{ Day 7 p.i. } \\
\hline & GIFU & DK & S-1 & 13 & GIFU & DK & S-1 & 13 \\
\hline $10^{9}$ & $5 / 5$ & $1 / 5$ & $5 / 5$ & $0 / 5$ & $5 / 5$ & $0 / 5$ & $5 / 5$ & $0 / 5$ \\
\hline $10^{8}$ & $5 / 5$ & $1 / 5$ & $5 / 5$ & $0 / 5$ & $5 / 5$ & $0 / 5$ & $5 / 5$ & $0 / 5$ \\
\hline $10^{7}$ & $5 / 5$ & $0 / 5$ & $4 / 5$ & $0 / 5$ & $5 / 5$ & $0 / 5$ & $3 / 5$ & $0 / 5$ \\
\hline $10^{6}$ & $4 / 4$ & $0 / 5$ & $3 / 5$ & $0 / 5$ & $5 / 5$ & $0 / 5$ & $3 / 5$ & $0 / 5$ \\
\hline $10^{5}$ & $4 / 5$ & $0 / 5$ & $3 / 5$ & $0 / 5$ & $3 / 5$ & $0 / 5$ & $3 / 5$ & $0 / 5$ \\
\hline
\end{tabular}

* Determined by faecal culture positivity for $C$. jejuni, and expressed as no. of mice with positive cultures of faecal specimens/no. of mice examined.

Table 2. Qualitative analyses of campylobacter infection in mice after oral inoculation Groups of 40 mice were orally infected with $10^{7}$ c.f.u. of strain GIFU or $10^{8}$ c.f.u. of strain DK. At intervals eight mice were killed to determine colonization of $C$. jejuni in each organ (see Methods).

\begin{tabular}{|c|c|c|c|c|c|c|c|c|c|c|}
\hline \multirow[b]{3}{*}{ Site } & \multicolumn{10}{|c|}{ Colonization of $C$. jejuni* } \\
\hline & \multicolumn{2}{|c|}{ Day 1} & \multicolumn{2}{|c|}{ Day 30} & \multicolumn{2}{|c|}{ Day 60} & \multicolumn{2}{|c|}{ Day 120} & \multicolumn{2}{|c|}{ Day 180} \\
\hline & GIFU & DK & GIFU & DK & GIFU & DK & GIFU & DK & GIFU & DK \\
\hline Small intestine & $8 / 8$ & $8 / 8$ & $7 / 8$ & $7 / 8$ & $7 / 8$ & $5 / 8$ & $6 / 8$ & $4 / 8$ & $6 / 8$ & - \\
\hline Caecum & $8 / 8$ & $8 / 8$ & $7 / 8$ & - & $5 / 8$ & - & $5 / 8$ & - & - & - \\
\hline Colon & $8 / 8$ & $8 / 8$ & $7 / 8$ & - & - & - & - & - & - & - \\
\hline Faeces & $8 / 8$ & $8 / 8$ & $8 / 8$ & - & $3 / 8$ & - & $2 / 8$ & - & $1 / 8$ & - \\
\hline Liver & - & - & $7 / 8$ & $6 / 8$ & $5 / 8$ & $3 / 8$ & $4 / 8$ & $2 / 8$ & - & - \\
\hline Gall bladder & - & - & $8 / 8$ & $8 / 8$ & $7 / 8$ & $7 / 8$ & $7 / 8$ & $7 / 8$ & $6 / 8$ & $6 / 8$ \\
\hline Blood & - & - & - & - & - & - & - & - & - & - \\
\hline
\end{tabular}

* No. of mice with culture positive/no. of mice examined; -, all examined mice were culture-negative.

Table 3. Quantitative cultures for C. jejuni in mice after oral inoculation of strain GIFU

Mice were orally infected with $10^{7}$ c.f.u. At intervals eight mice were killed and the intestines and organs processed (see Methods) to obtain colony counts. The figures represent the mean values for eight mice at each sampling time. -, No colonies formed on Skirrow's medium at $72 \mathrm{~h}$.

Viable counts $\left[\log _{10}\right.$ (c.f.u. per g tissue)]

\begin{tabular}{|c|c|c|c|c|c|c|c|c|c|c|}
\hline \multirow[b]{2}{*}{ Site } & \multicolumn{4}{|c|}{ Days p.i. } & \multicolumn{6}{|c|}{ Months p.i. } \\
\hline & 1 & 3 & 5 & 7 & 1 & 2 & 3 & 4 & 5 & 6 \\
\hline \multicolumn{11}{|l|}{ Small intestine } \\
\hline Upper half & $4 \cdot 2$ & $3 \cdot 5$ & $3 \cdot 2$ & $2 \cdot 8$ & $3 \cdot 3$ & $2 \cdot 7$ & $1 \cdot 6$ & $2 \cdot 8$ & 1.8 & $1 \cdot 3$ \\
\hline Lower half & $3 \cdot 4$ & $2 \cdot 7$ & $2 \cdot 1$ & $2 \cdot 4$ & $1 \cdot 5$ & $1 \cdot 8$ & $2 \cdot 0$ & 1.8 & $1 \cdot 4$ & $<1 \cdot 0$ \\
\hline Caecum & $3 \cdot 8$ & $3 \cdot 4$ & $2 \cdot 5$ & $2 \cdot 0$ & $2 \cdot 6$ & $2 \cdot 0$ & $1 \cdot 2$ & $<1.0$ & $<1.0$ & - \\
\hline Colon & $3 \cdot 3$ & $4 \cdot 0$ & $3 \cdot 4$ & $3 \cdot 2$ & 1.7 & - & - & - & - & - \\
\hline Liver & - & - & $<1 \cdot 0$ & $1 \cdot 4$ & 3.4 & $3 \cdot 3$ & $2 \cdot 6$ & $2 \cdot 3$ & $2 \cdot 2$ & - \\
\hline Gall bladder & - & - & $1 \cdot 5$ & 1.8 & $2 \cdot 0$ & 3.5 & $2 \cdot 8$ & $2 \cdot 5$ & $2 \cdot 7$ & 1.6 \\
\hline
\end{tabular}

specimens of conrol and uninfected mice. In the late stage of infection (between months 4 and 5), fluorescence was seen only at the portal triads.

\section{Liver function tests}

Liver function tests were normal during the first 3 weeks after inoculation. Thereafter, ALP, GOT and LDH activities gradually increased and mild elevations were apparent at 1 month p.i. 
Table 4. Liver function tests in mice orally inoculated with $10^{7}$ c.f.u. of strain GIFU

Data were obtained from four mice and are expressed as the mean of four samples \pm SD. Values in parenthesis are the means of results for four control mice at each time. GOT, GPT and LDH are expressed in $\mathrm{IU}^{-1}$, ALP in KAU and serum albumin in $\mathrm{mg}^{-1}$.

\begin{tabular}{|c|c|c|c|c|c|c|}
\hline \multirow[b]{2}{*}{ Test } & \multicolumn{6}{|c|}{ Months p.i.: } \\
\hline & 1 & 2 & 3 & 4 & 5 & 6 \\
\hline GOT & $\begin{array}{c}130 \pm 21 \\
(58 \cdot 5)\end{array}$ & $\underset{(62 \cdot 4)}{150 \pm 18}$ & $\begin{array}{c}110 \pm 16 \\
(56 \cdot 7)\end{array}$ & $\begin{array}{c}100 \pm 24 \\
(59 \cdot 3)\end{array}$ & $\begin{array}{c}100 \pm 13 \\
(60 \cdot 2)\end{array}$ & $\begin{array}{c}95 \pm 12 \\
(56 \cdot 5)\end{array}$ \\
\hline GPT & $\begin{array}{c}50 \pm 6 \\
(30 \cdot 2)\end{array}$ & $\begin{array}{c}80 \pm 12 \\
(30 \cdot 8)\end{array}$ & $\begin{array}{c}90 \pm 16 \\
(28 \cdot 9)\end{array}$ & $\begin{array}{c}130 \pm 14 \\
(31 \cdot 4)\end{array}$ & $\begin{array}{c}75 \pm 9 \\
(29 \cdot 7)\end{array}$ & $\begin{array}{c}38 \pm 6 \\
(31 \cdot 2)\end{array}$ \\
\hline ALP & $\begin{array}{c}24 \cdot 8 \pm 1 \cdot 5 \\
(16 \cdot 4)\end{array}$ & $\begin{array}{c}18.9 \pm 2 \cdot 7 \\
(17 \cdot 2)\end{array}$ & $\begin{array}{c}16 \cdot 4 \pm 1 \cdot 8 \\
(15 \cdot 3)\end{array}$ & $\begin{array}{c}15 \cdot 6 \pm 2 \cdot 0 \\
(16 \cdot 2)\end{array}$ & $\begin{array}{c}14 \cdot 3 \pm 1 \cdot 7 \\
(14 \cdot 9)\end{array}$ & $\begin{array}{c}13 \cdot 2 \pm 2 \cdot 4 \\
(15 \cdot 6)\end{array}$ \\
\hline LDH & $\begin{array}{c}400 \pm 21 \\
(120 \cdot 7)\end{array}$ & $\begin{array}{c}450 \pm 32 \\
(116 \cdot 7)\end{array}$ & $\begin{array}{c}380 \pm 18 \\
(132 \cdot 4)\end{array}$ & $\begin{array}{c}300 \pm 24 \\
(128.6)\end{array}$ & $\begin{array}{c}275 \pm 32 \\
(118.9)\end{array}$ & $\begin{array}{c}200 \pm 16 \\
(121 \cdot 2)\end{array}$ \\
\hline Albumin & $\begin{array}{c}4.5 \pm 0.8 \\
(5 \cdot 0)\end{array}$ & $\underset{(5.4)}{4.0 \pm 0.4}$ & $\frac{3.0 \pm 0.3}{(4.9)}$ & $2 \cdot 8 \pm 0.2$ & $2 \cdot \underset{(5 \cdot 2)}{2.6} 0 \cdot 1$ & $2 \cdot 4 \pm 0.2$ \\
\hline $\begin{array}{l}\text { Albumin/ } \\
\text { globulin }\end{array}$ & $\begin{array}{c}1 \cdot 4 \pm 0.2 \\
(1.8)\end{array}$ & $\begin{array}{c}1 \cdot 1 \pm 0.3 \\
(1.9)\end{array}$ & $\begin{array}{c}0.9 \pm 0.2 \\
(2 \cdot 1)\end{array}$ & $\begin{array}{c}0.7 \pm 0.2 \\
(2 \cdot 2)\end{array}$ & $\begin{array}{c}0.6 \pm 0.1 \\
(1.9)\end{array}$ & $\begin{array}{c}0.4 \pm 0 \cdot 2 \\
(1 \cdot 7)\end{array}$ \\
\hline
\end{tabular}

(Table 4). The elevation of GPT was slightly slower (Table 4). The elevation of these enzyme activities strongly indicated damage to parenchymal cells in the liver and the liver function of infected mice was most affected 2 months after inoculation. Thereafter serum levels of GOT, ALP, and LDH gradually decreased. However, the serum level of GPT was highest at 4 months p.i. and thereafter returned to normal. The slight elevation of GOT and LDH at 6 months p.i. indicated persistent focal liver damage. Hypoalbuminaemia became prominent in the late stage of infection, providing further evidence of hepatocellular damage: the ratio of albumin to globulin was less than 0.4 (normal, 0.9-1.6) at 6 months p.i. There were no significant differences in liver function tests between normal control mice and uninfected mice of challenged groups.

\section{DISCUSSION}

The results of this study demonstrate that the oral inoculation of $C$. jejuni in mice can induce hepatitis characterized by parenchymal focal infiltrative necrosis in the absence of diarrhoea. The presence of hepatocellular damage was indicated by elevations of transaminases, LDH and ALP. This was directly confirmed by histopathological demonstration of focal infiltrative necrosis of the liver parenchyma and inflammatory nodules in portal triads. These changes were mild, unlike those observed in viral hepatitis. Six months p.i. campylobacter organisms could not be recovered from the liver but hepatic lesions became extensive.

Our results and those of Blaser et al. (1983) were at variance and several factors such as differences in the strain of mice, differences in their intestinal flora or differences in the virulence of $C$. jejuni strains used may account for this. Furthermore, $C$. jejuni could not be recovered from the liver and gall bladder when specimens were homogenized using homogenizers. Thus, in this study organ specimens were carefully minced using scissors in warmed tryptic soy broth supplemented with L-cysteine. We have found that another important factor which results in enhanced oral infectivity of $C$. jejuni for mice is the culture of the organisms in liquid medium prior to inoculation. Ruiz-Palacios et al. (1983) reported a culture medium supplemented with amino acids. $C$. jejuni grown in this medium had relatively high infectivity in mice by oral inoculation (unpublished data). These factors could account for a wide variation in the infectivity of $C$. jejuni in mice as well as in the prevalence of biliary carriage.

The route by which organisms reach the liver could not be clarified in this study but from human clinical studies (Guerrant et al., 1978), there is a possibility that organisms may spread systematically via the bloodstream during the early phase of infection. This is supported experimentally by the fact that $C$. jejuni can be recovered from the blood and liver of infected mice within $60 \mathrm{~min}$ of oral inoculation (Blaser et al., 1983). However, histological findings 

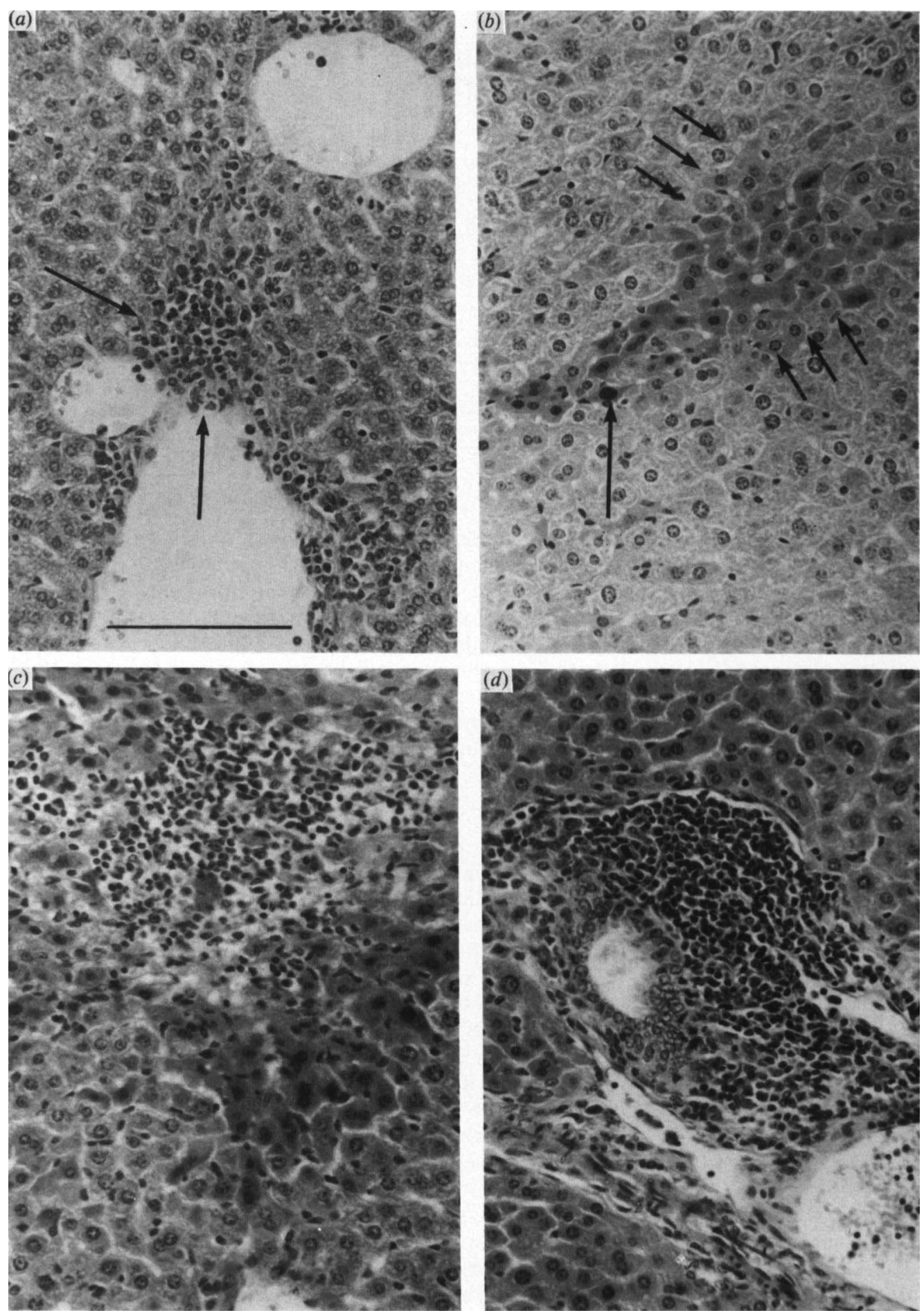

Fig. 1. Histological changes in the liver of infected mice various times p.i. The bar represents $100 \mu \mathrm{m}$ (magnification the same for all the photographs). (a) Inflammatory cell infiltrate (arrows) in the vicinity of the central vein at 2 weeks p.i. (b) Focal cellular changes of the parenchyma at 1 month p.i., showing increased cytoplasmic staining intensity (short arrows) and pyknotic nucleus (long arrow) of hepatocytes. (c) Focal necrosis with inflammatory cell response at 2 months p.i. (d) Marked inflammatory nodule at the portal triad between days 30 and 60 p.i. 

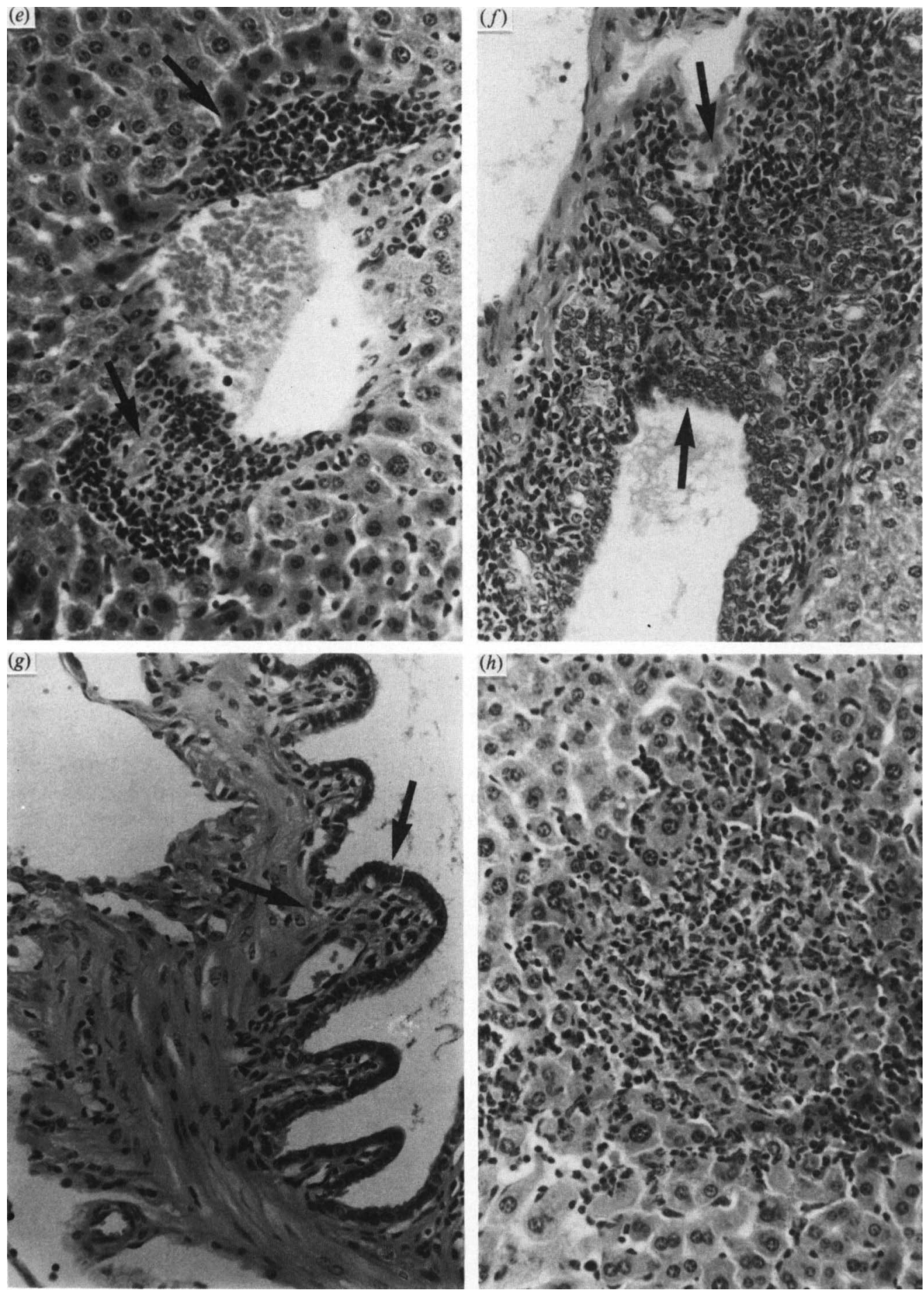

(e) Prominent inflammatory cell responses (arrows) around the central vein 3 months p.i. ( $f$ ) Extensive periportal inflammatory responses (arrows) at 4 months p.i. (g) Enlarged gall bladder with oedematous epithelial layer (arrows) at 4 months p.i. (h) Formation of focal infiltrative necrosis in the parenchyma 4 to 6 months p.i. 


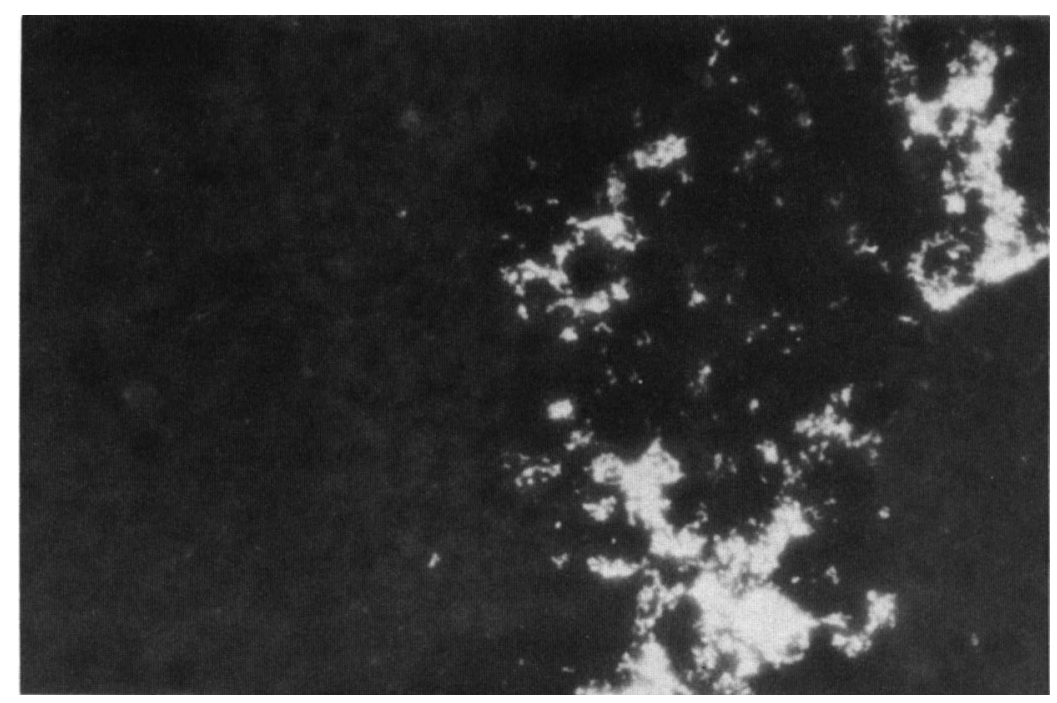

Fig. 2. Direct immunofluorescence of a tissue section of the liver from an infected mouse (2 months p.i.) reacted with hyperimmune antiserum against $C$. jejuni strain GIFU. Specific immunofluorescence is observed at portal triads but not intracellularly in the hepatocytes. Magnification as for Fig. 1.

showing marked infiltration around the portal triads suggest that $C$. jejuni may ascend to the liver via bile ducts in the late phase of infection. The ability of $C$. jejuni to persist in the hepatobiliary tract varied with the strain studied, although limited numbers of strains were used.

There are, in fact, a few reports of hepatic pathology in human $C$. jejuni enteritis. Ampelas et al. (1982) described bacteraemic hepatitis with the presence of necrosis and inflammatory cells in liver biopsy material from a patient with $C$. coli enteritis. Reddy \& Thomas (1982) described a case with $C$. jejuni enteritis and sharply deranged liver function tests. Pitkänen et al. (1983) reported increased activity of transaminases (GOT and GPT) in $13.6 \%$ of a large number of patients with $C$. jejuni enteritis in Helsinki. Thus, hepatic involvement following $C$. jejuni gastroenteritis might be seen not only in animals but also in humans.

Recently, Kiehlbauch et al. (1985) reported that $C$. jejuni is readily phagocytosed by human mononuclear phagocytes in the absence of specific opsonins but continues to survive intracellularly for at least $6 \mathrm{~d}$. This does not mean that $C$. jejuni is one of the facultative intracellular parasites such as Salmonella typhi, which can survive intracellularly for several weeks. However, the enhanced survival of intracellular $C$. jejuni in human mononuclear phagocytes possibly suggests that $C$. jejuni can persist in the liver like $S$. typhi, although the pathological changes of the liver are different.

The results obtained in this study raise the possibility that hepatic lesions characterized by focal infiltrative necrosis might be associated with $C$. jejuni infections in humans.

This work was supported in part by the Yakult Foundation for research for enteric infections. We thank E. Yabuuchi for providing strain GIFU of $C$. jejuni, H. Nakanishi for serotyping all strains, and T. Masutani for identification of $C$. jejun i strains. We are grateful to $\mathrm{H}$. Nakano and $\mathrm{S}$. Imai for help in reading sections of the liver. The authors greatly appreciate the assistance of I. Matsuda in the preparation of this manuscript.

\section{REFERENCES}

Amador, E., Dorfman, L. E. \& Wacker, W. E. C. (1963). Serum lactic dehydrogenase activity: an analytical assessment of current assays. Clinical Chemistry 9, 391-399.

Ampelas, M., Perz, C., Jourdan, J., Nalet, B.,
Raynaud, A., Emberger, J. M. \& Michel, H. (1982). Hépatite à Campylobacter coli. Nouvelle Presse Médicale 11, 593-595.

Blaser, M. W., Berkowitz, I. D., LaForce, F. M., Cravens, J., Reller, L. B. \& Wang, W.-L. L. 
(1979). Campylobacter enteritis: clinical and epidemiologic features. Annals of Internal Medicine 91, 179-185.

Blaser, M. J., Duncan, D. J., Warren, G. H. \& Wang, W.-L. L. (1983). Experimental Campylobacter jejuni infection of adult mice. Infection and Immunity 39, 908-916.

Butzler, J. P. \& Skirrow, M. B. (1979). Campylobacter enteritis. Clinics in Gasteroenterology 8, 737765.

Caldwell, M. B., Walker, R. I., Stewart, S. D. \& ROGERS, J. E. (1983). Simple adult rabbit model for Campylobacter jejuni enteritis. Infection and Immunity 42, 1176-1182.

Drake, A. A., Gilchrist, M. J. R., Washington, J. A., Huizenga, K. A. \& VANScoY, R. E. (1981) Diarrhea due to Campylobacter fetus subspecies jejuni. A clinical review of 63 cases. Mayo Clinic Proceedings 56, 414-423.

GUERRANT, R. L., ROBERT, R. G., WINN, W. C., JR \& ROBERTS, R. B. (1978). Campylobacteriosis in man: pathogenic mechanisms and review of 91 bloodstream infections. American Journal of Medicine 65, 584-592.

Johnson, G. D., Holborow, E. J. \& Dorling, J. (1978). Immunofluorescence and immunoenzyme techniques. In Handbook of Experimental Immuno$\log y$, 3rd edn, pp. 15.1-15.30. Edited by D. M. Weir. Oxford: Blackwell Scientific Publications.

KaRmen, A., WŔoblewSKI, F. \& LADUE, J. S. (1955). Transaminase activity in human blood. Journal of Clinical Investigation 34, 126-133.

Kiehlbauch, J. A., Alback, R. A., Baum, A. L. \& Chang, K. P. (1985). Phagocytosis of Campylobacter jejuni and its intracellular survival in mononuclear phagocytes. Infection and Immunity 48, 446-451.

KIND, P. R. N. \& KING, E. J. (1954). Estimation of plasma phosphatase by determination of hydrolysed phenol with amino-antipytine. Journal of Clinical Pathology 7, 322-326.

Klipstein, F. A. \& ENGert, R. F. (1984). Properties of crude Campylobacter jejuni heat-labile enterotoxin. Infection and Immunity 45, 314-319.

KoHN, J. (1958). Small-scale membrane filter electrophoresis and immuno-electrophoresis. Clinica chimica acta 3, 450-454.

LAMbert, M. E., Schofield, P. F., Ironside, A. G. \& MANDEL, B. K. (1979). Campylobacter colitis. British Medical Journal 1, 857-859.

Miles, A. A. \& MisRa, S. (1938). The estimation of the bacteriocidal power of the blood. Journal of Hygiene 38, 732-749.

Penner, J. L. \& Hennessy, J. N. (1980). Passive hemagglutination technique for serotyping Campylobacter fetus subsp. jejuni on the basis of soluble heatstable antigens. Journal of Clinical Microbiology 12, 732-737.

Pitkänen, T., PönkÄ, A., Pettersson, R. \& Kosunen, T. U. (1983). Campylobacter enteritis in 188 hospitalized patients. Archives of Internal Medicine 143, 215219.

RedDy, K. R. \& Thomas, E. (1982). Campylobacter jejuni enterocolitis and hepatitis. Gastroenterology 82, 1156.

Ruiz-Palacios, G. M., Escamilla, E. \& Torres, N. (1981). Experimental Campylobacter diarrhea in chickens. Infection and Immunity 34, 250-255.

Ruiz-Palacios, G. M., Torres, J., TORres, N. I., Escamilla, E., Ruiz-Palacios, B. R. \& Tamayo, J. (1983). Cholera-like enterotoxin produced by Campylobacter jejuni. Lancet ii, 250-253.

SKIRROW, M. B. (1977). Campylobacter enteritis: 'new' disease. British Medical Journal 2, 9-11. 